\title{
A Doctor in the Headlights
}

Adam Szulewski, MD, MHPE

$\mathrm{O}$ ne of my dreams as a child was to fly a plane. Of course, I never became a pilot, but I recently had the opportunity to fly in a high-fidelity full-flight simulator-the same one used by airline pilots for their training. After a short introduction to the airplane's controls and an overview of the standard flight checklists, I was "up in the air." At the end of the short flight (and a very bumpy landing), the captain turned to me and asked what I thought of the experience. With my hands still gripping the controls tightly, I told him that, above all else, flying the plane gave me a visceral sensation of cognitive overload-something I hadn't felt in years.

From the moment I took the controls of my simulated flight, I could accomplish only a few basic tasks despite the coaching of the captain seated to my left. On takeoff, my hands gripped the yoke tightly as I focused on the controls. Pull to go up, push to go down. While cruising along, my eyes were glued looking straight ahead. Keep the horizon level. When it was my turn to land, I answered the captain with short responses. "My aircraft." But that's where it ended. Each additional stimulus, whether it was communicating with air traffic control or processing simple instructions, put a palpable strain on my working memory. Even my ability to go through the standard flight checklists was, for the most part, lost. I didn't have an ounce of situational awareness. To say that I was cognitively overloaded doesn't do justice to that visceral feeling.

Though I hadn't felt that way for some time, that feeling was familiar. It reminded me of the way I felt managing a few difficult cases as a junior resident. One example sticks out in my mind. It was the middle of the night and I was called to assess a patient in the step-down ICU. A patient there had suddenly developed hypoxia and labored breathing. He had no air entry on the left side. He looked, in one word, unwell. As I quickly worked through the list of causes of sudden hypoxia and unilateral absent air entry in my head, I realized that I was going to have to needle decompress this man's tension pneumothorax. I was both physiologically stressed-as I had never performed this procedure on a real patient, let alone unsupervised on a real patient - and cognitively overloaded.

But while the visceral response and discomfort I felt was familiar, the experience in the flight simulator was far more profound for some reason. Perhaps it's the time that's passed since I was a junior resident and I've simply forgotten. But I wonder whether having no experience whatsoever flying a plane had more to do with it. At least as a junior resident, I had practiced both the act of needle decompressing a patient's chest and the act of making the decision to act many times in the simulation lab. In fact, this scenario was a perennial favorite in simulation teaching during my emergency medicine residency. And so, when I was tasked to perform the procedure in the real world, I wasn't paralyzed.

In the flight simulator, on the other hand, I was immediately out of my element. Taking control of the keyboard on my IBM 486 and playing Flight Simulator 3.0 as a seven-year-old was the closest I'd ever been to the inside of an aircraft cockpit until that day. In the high-fidelity full-flight simulator, I had completely bought in and suspended all disbelief thanks to the fidelity of the simulator, with its true-to-life visuals, movements, sounds, and haptic feedback. As far as my brain was concerned, I was flying a real plane

From the Department of Emergency Medicine (AS), Queen's University, Kingston, Ontario, Canada

Received December 27, 2018; accepted January 2, 2019.

The author has no relevant financial information or potential conflicts to disclose.

Supervising Editor: Susan B. Promes, MD.

Address for correspondence and reprints: Adam Szulewski, MD, MHPE; e-mail: aszulewski@qmed.ca.

AEM EDUCATION AND TRAINING 2019;3:200-201 
without the benefit of having practiced in a flight simulator first.

I hadn't fully appreciated the profound impact that simulation training had on my career until the conversation with the captain after my simulated flight that day. Resuscitation-focused simulation was a central part of my emergency medicine training and I was lucky enough to have had the opportunity to learn and teach in the simulation lab at least once a week for five years as a resident. Looking back on it, I took this experience for granted. It was practice in the medical simulator that had prepared me for that night of call in the hospital. And it was a lack of practice in the flight simulator that made me feel overwhelmed flying the simulated plane.

But in addition to emphasizing the importance of simulation in my own training, this experience has opened my eyes in another way. As a simulation educator, I can't help thinking about the parallels between the way I felt as a novice pilot and the way my novice learners must feel the first time they step foot in the simulation lab. That feeling of vulnerability in a new and unfamiliar environment is an important emotion for all teachers to remember. It becomes all too easy to forget, until you find yourself trapped in the headlights again. 